\title{
Synthesis of Carbon Nanotube by Chemical Vapor Deposition (CVD) Method
}

\author{
Munaly Akter \\ Research Fellow \\ Department of Materials Science and Engineering \\ University of Rajshahi \\ Rajshahi, Bangladesh \\ E-mail: akter_munaly88@yahoo.com
}

Dr. Md. Ehasanul Haque*

Assistant Professor, Department of Physics

American International University-Bangladesh (AIUB)

Dhaka, Bangladesh

E-mail: ehasanul@aiub.edu

\author{
Md. Masud Parvez \\ Assistant Professor, Department of Physics \\ American International University-Bangladesh (AIUB) \\ Dhaka, Bangladesh \\ E-mail: masud.parvez@aiub.edu
}

\author{
Dr. Md. Abdul Matin \\ Professor, Department of Materials Science and Engineering \\ University of Rajshahi \\ Rajshahi, Bangladesh \\ E-mail: matinmst@ru.ac.bd
}

\section{*Corresponding Author: ehasanul@aiub.edu}

DOI: $10.31364 / \mathrm{SCIRJ} / \mathrm{v} 8.16 .2020 . P 0620780$

http://dx.doi.org/10.31364/SCIRJ/v8.i6.2020.P0620780

\begin{abstract}
We synthesize the carbon nanotube (CNT) by chemical vapor deposition (CVD). The morphological images have been observed before and after the CNT growth on the $\mathrm{Si} / \mathrm{SiO}_{2} / \mathrm{Co}$ substrate. Scanning electron microscope (SEM) images confirmed the growth of CNT onto the $\mathrm{Si} / \mathrm{SiO}_{2} / \mathrm{Co}$ substrate. The $\mathrm{SEM}$ image of $\mathrm{Si} / \mathrm{SiO}_{2} / \mathrm{Co}$ substrate having no $\mathrm{CNT}$ was found little dark due to having Co catalyst on the top, whereas lots of amorphous carbon was existed on the $\mathrm{Si} / \mathrm{SiO}_{2} / \mathrm{Co} / \mathrm{CNT}$ surface according to SEM image. The growing CNT has no regularity and directionality.
\end{abstract}

Index Terms-Carbon Nanotube, Chemical Vapor Deposition, Morphology, Amorphous Carbon

\section{INTRODUCTION}

Carbon nanotubes (CNTs) have been recognized originally by Sumiolijima in 1991 [1]. CNTs are made of carbon atom by rolling up a graphene sheet with tubular nanostructure. CNTs have large variety of physical properties due to having different individual graphene layer which is rolled up into a tube. The wide variety of electronic structures in combination with a mechanically strong nanoscale lattice and outstanding optical properties are among the main reasons for the large interest in using CNTs in future electric and optical applications [2]. Due to having many interesting features and applications in the field of electronics, optics, and medicines, it needs precise fabrication and quality assurance.

There are several methods to fabricate the CNT such as laser ablation, arc discharge, chemical vapor deposition (CVD) and so on. Among them chemical vapor deposition (CVD) method is easy and cost effective. This method is capable of high-quality, defect free and large-scale production of CNT. Furthermore, it could be possible to gain control over the various parameters which are involved in CVD experiments. In this process, $\mathrm{P}^{+}-\mathrm{Si}$ with $200 \mathrm{~nm}$ thickness of $\mathrm{SiO}_{2}$ is used as a substrate. Cobalt nanoparticles and ethanol are used as the catalyst and carbon source respectively for CNT growth. 
CVD synthesis can be divided into two main categories: Supported catalyst growth and floating or gas-phase growth. In the supported growth process, the catalyst is prepared in advance and deposited in some way on a support medium. This is inserted into a flow apparatus, typically a tube at atmospheric pressure in a temperature-controlled furnace, where it can be exposed to flowing carbon-rich gas at elevated temperatures (typically $500-1100^{\circ} \mathrm{C}$ ) for a certain period. For floating-catalyst growth, a high-temperature flow-furnace is still used, however the catalyst and carbon source are injected into the system simultaneously, either in gas phase or as an aerosol, where the subsequent decomposition and reaction can either occur completely suspended in the gas flow or following self-deposition on a surface in the reactor.

Supported growth is the most widely used CVD-based method of nanotube synthesis. The type of catalyst used, the way in which it is prepared and the choice of support all have significant impact on the nature of the material produced. The most common support media are metallic Si and Si wafers [311] or various $\mathrm{SiO}_{2}$ based materials, [12-15] although graphite and various metallic thin films have also been used [16-19]. $\mathrm{Fe}, \mathrm{Co}$, and $\mathrm{Ni}$ have proven to be the most successful catalysts, with Fe being the most frequently used. The catalysts are often deposited as small particles or islands on the substrate and result in localized mats of nanotubes sprouting from the catalyst covered areas. Electrochemical, lithographic, sputtering, spin coating, and other techniques are commonly used for catalyst deposition.

An interesting observation is that the diameter of the carbon nanotube becomes proportional to the particle size when it is reduced to the scale of single tubes (a few or few $10 \mathrm{~s}$ of nanometers) [13] making it possible to tune the nanotube diameter by controlling the catalyst deposition. Acetylene is the most widely used hydrocarbon, with methane, ethylene, propylene, and a few aromatic compounds also finding common use. Preparing the catalyst in advance provides the opportunity to define specific patterns on the substrate. The ability to control the position and direction of growth could have significant benefits, including simple routes to achieving nanotube-based electronic devices. Techniques such as photolithography, [7,20] electron beam lithography, [5,21,22] laser etching, [14,15] micromoulding, [23] and even ink-jet printing [24] have been successfully used to achieve patterned nanotube growth.

Both Cheng et al. [25] and Yang et al. [26] describe the production of macroscopic fibers of SWNT using a combination of ferrocene, benzene, and thiophene in a dualfurnace system. The fibers, observed to be up to $100 \mathrm{~mm}$ in diameter and a few centimeters in length, were composed of numerous roughly aligned bundles of individual SWNT with diameters of 1.5-3.0 nm. Ago et al. observed the production of SWNT by injecting a colloidal solution of CoMo nanoparticles $\left(11 \mathrm{~nm}\right.$ diameter) in toluene into a $1200^{\circ} \mathrm{C}$ oven [27]. With the addition of $1 \%$ thiophene to the solution SWNT with diameters of 1.1-1.9 nm was favored, while using $10 \%$ thiophene resulted in only MWNT. A group at Rice University has developed a very successful method of SWNT synthesis using CO $[28,29]$. Bronikowski et al. useed high pressure jets (up to $10 \mathrm{~atm})$ of preheated $\mathrm{CO}$ to rapidly heat mixtures of iron pentacorbonyl in $\mathrm{CO}$ as they enter a high-temperature furnace $\left(900-1100^{\circ} \mathrm{C}\right)[29]$.

In this work, we used chemical vapor deposition (CVD) technique to fabricate the carbon nanotubes due to having some unique advantages compared to the other techniques. Arc discharge and laser vaporization are both batch-scale processes which ultimately limit their production capacities. However, CVD is most promising method which potentially offers controlled synthesis and continuous operation. The energy required is lower. The carbon feedstocks are abundant and inexpensive. The setup of process is simple and it is easy to control and manipulate. In this process, CNT are synthesized with high quality and large scale production. With these aforementioned advantages, CVD method was chose to synthesize CNT in this work. Characterization including SEM analysis has been carried out to ensure quality fabrication and to explore the correct mechanism for CNT production.

\section{MATERIALS AND METHODS}

Chemical Vapor Deposition (CVD) technique was used to synthesize CNT. In this system, ethanol was used as the carbon source to synthesize CNT. Temperature was controlled by a temperature controller. Argon gas, which was managed by a mass-flow controller, was used to keep the pressure inside the chamber stable before and after supplying ethanol. A rotary pump was used to make vacuum inside the chamber. Chamber's pressure value was displayed by a manometer. In order to fabricate $\mathrm{CNT}$ on $\mathrm{Si} / \mathrm{SiO}_{2} / \mathrm{Co}$ substrate, a commercial $\mathrm{SiO}_{2}(100 \mathrm{~nm}) / \mathrm{p}^{+}-\mathrm{Si}$ substrate was cleaned with piranha solution. Then, we deposited 5-nm-thick cobalt film as the catalyst onto the substrate by using e-beam evaporator MUEECO-EB (ALVAC) with deposition rate of $0.01 \mathrm{~nm} / \mathrm{s}$. The substrate with Co catalyst thin film was introduced into the CVD system for CNT growth. Firstly, the quartz tube chamber was evacuated to around $10 \mathrm{~Pa}$ to pull out residual oxygen gas in the upper part of ethanol bottle at $800^{\circ} \mathrm{C}$. Then the furnace was cooled down in order to put the sample into chamber. The chamber was then evacuated while increasing temperature. After reaching a desired temperature $\left(850^{\circ} \mathrm{C}\right)$, Ar gas $(100$ $\mathrm{sccm}$ ) was introduced by mass flow controller for 10 minutes in order to get thermal equilibrium state of the whole system. Then ethanol was introduced into the chamber so that the pressure was kept fixed at $400 \mathrm{~Pa}$ for $30 \mathrm{~min}$. After growing CNTs, the chamber was cooled down to room temperature naturally in order to take out the sample. The as-grown CNT was investigated by scanning electron microscopy (SEM) image.

\section{RESULTS AND DISCUSSION}

SEM analysis has been conducted to confirm the fabrication of CNTs. Fig. 1(a) and 1(b) exhibits the morphological images of $\mathrm{Si} / \mathrm{SiO}_{2} / \mathrm{Co}$ substrate and CNT grown on $\mathrm{Si} / \mathrm{SiO}_{2} / \mathrm{Co}$ substrate respectively. It seemed that, lots of amorphous carbon was existed on the $\mathrm{Si} / \mathrm{SiO}_{2} / \mathrm{Co} / \mathrm{CNT}$ surface according to SEM image. The magnification for both the SEM images was $2 \mu \mathrm{m}$. 


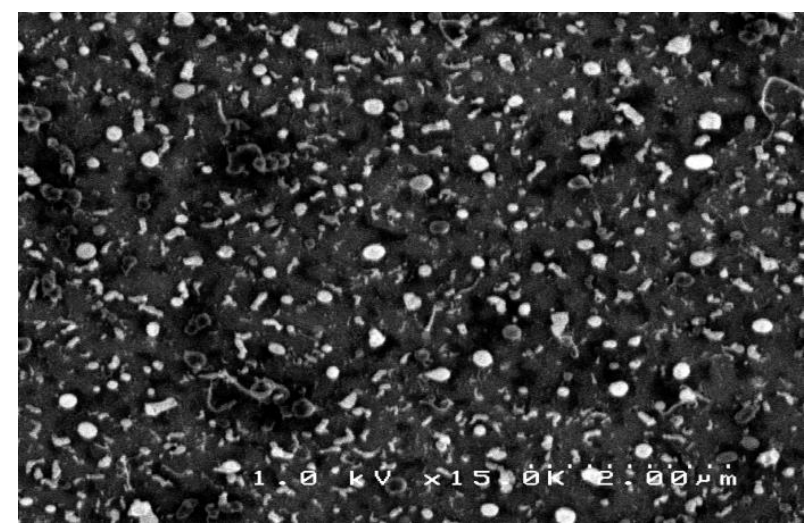

(a)

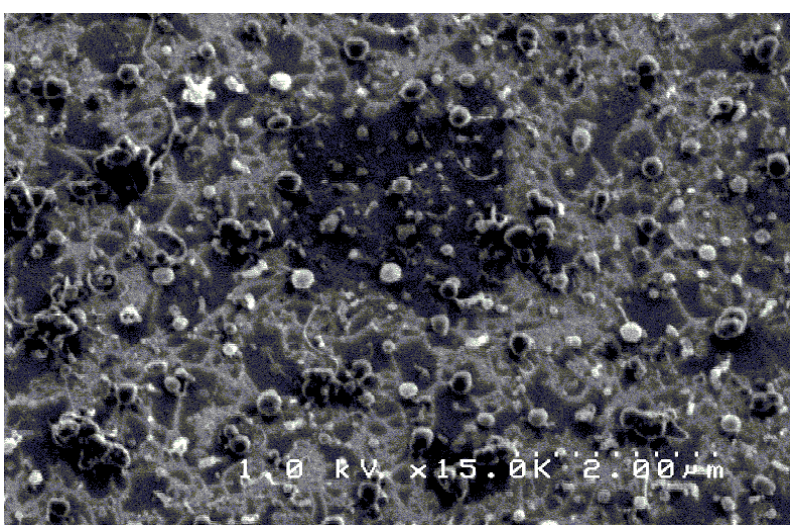

(b)

Fig. 1. SEM image of (a) $\mathrm{Si} / \mathrm{SiO}_{2} /$ Co substrate

(b) $\mathrm{Si} / \mathrm{SiO}_{2} / \mathrm{Co}$ substrate with randomly grown CNT.

Fig. 1(a) exhibit the SEM image of $\mathrm{Si} / \mathrm{SiO}_{2} / \mathrm{Co}$ substrate which looked little black and this is due to the cobalt catalyst on the top. However, CNT randomly grown on $\mathrm{Si} / \mathrm{SiO}_{2} / \mathrm{Co}$ substrate is shown clearly in Fig. 1(b). The growing CNT has no regularity and directionality. But the morphological image confirmed the growth of CNT onto the $\mathrm{Si} / \mathrm{SiO}_{2} / \mathrm{Co}$ substrate.

\section{CONCLUSION}

Chemical vapor deposition (CVD) shows the greatest promise as a true industrial scale process, particularly floating catalyst techniques which, in principle, can be operated in a continuous fashion. The prospects of controlled patterned growth are also very favorable for applications like molecular scale sensors, mechanical and electronic devices. Due to having such unique character and advantages we chose to synthesize CNT by CVD method. We observed the morphological images before and after the CNT growth on the $\mathrm{Si} / \mathrm{SiO}_{2} / \mathrm{Co}$ substrate. Scanning electron microscope (SEM) images confirmed the growth of $\mathrm{CNT}$ onto the $\mathrm{Si} / \mathrm{SiO}_{2} / \mathrm{Co}$ substrate. The SEM image of $\mathrm{Si} / \mathrm{SiO}_{2} / \mathrm{Co}$ substrate having no CNT was found little dark due to having Co catalyst on the top, whereas lots of amorphous carbon was existed on the
$\mathrm{Si} / \mathrm{SiO}_{2} / \mathrm{Co} / \mathrm{CNT}$ surface according to SEM image. The growing CNT has no regularity and directionality.

\section{ACKNOWLEDGEMENT}

We acknowledged to the Center of Nanotechnology Research (CNR) situated in American International University Bangladesh for the laboratory facility.

\section{REFERENCES}

[1]. S. lijima, "Helical micortubes of graphitic carbon", Nature, vol. 354, pp. 56-58, 1991.

[2]. P. Avouris, Z. H. Chen and V. Perebeinos, "Carbonbased electronics, Natæe Nanotechnology", vol. 2, no. 10, pp. 605-615, 2007.

[3]. C. J. Lee, D. W. Kim, T. J. Lee, Y. C. Choi, Y. S. Park, W. S. Kim, Y. H. Lee, W. B. Choi, N. S. Lee, J. M. Kim, Y. G. Choi and S. C. Yu, "Synthesis of uniformly distributed carbon nanotubes on a large area of Si substrates by thermal chemical vapor deposition,” Appl. Phys. Lett., vol. 75, pp. 1721-1723, 1999.

[4]. J. Kong, H. T. Soh, A. M. Cassel, C. F. Quate and H. Dai, "Synthesis of individual single-walled carbon nanotubes on patterned silicon wafers", Nature, vol. 395, pp. 878-881, 1998.

[5]. S. Fan, M. G. Chapline, N. R. Franklin, T. W. Tombler, A. M. Cassell and H. Dai, "Self-oriented regular arrays of carbon nanotubes and their field emission properties", Science, vol. 283, pp. 512-514, 1999.

[6]. D. Xu, G. Guo, L. Gui, Y. Tang, Z. Shi, Z. Jin, Z. Gu, W. Liu, X. Li and G. Zhang, "Controlling growth and field emission property of aligned carbon nanotubes on porous silicon substrates", Appl. Phys. Lett., vol. 75, pp. 481-483, 1999.

[7]. S. Huang and A. H. W. Mau, "Aligned carbon nanotubes patterned photolithographically by silver", Appl. Phys. Lett., vol. 82, pp. 796-798, 2003.

[8]. K. H. Lee, J. M. Cho and W. Sigmund, "Control of growth orientation for carbon nanotubes", Appl. Phys. Lett., vol. 82, pp. 448-450, 2003.

[9]. M. P. Siegal, D. L. Overmyer and P. P. Provencio, "Precise control of multiwall carbon nanotube diameters using thermal chemical vapor deposition", Appl. Phys. Lett., vol. 80, pp. 2171-2173, 2002.

[10]. C. L. Cheung, A. Kurtz, H. Park and C. M. Lieber, "Diametercontrolled synthesis of carbon nanotubes", J. Phys. Chem. B, vol. 106, pp. 2429-2433, 2002.

[11]. B. Q. Wei, Z. J. Zhang, P. M. Ajayan and G. Ramanath, "Growing pillars of densely packed carbon nanotubes on Ni-coated silica", Carbon, vol. 40, pp. 47-51, 2002.

[12]. C. J. Lee and J. Park, "Growth model of bambooshaped carbon nanotubes by thermal chemical vapor deposition", Appl. Phys. Lett., vol. 77, pp. 3397-3399, 2000.

[13]. O. A. Nerushev, S. Dittmar, R. E. Morjan, F. Rohmund and E. E. B. Campbell, "Particle size dependence and model for ironcatalyzed growth of carbon nanotubes by thermal chemical vapor deposition", J. Appl. Phys., vol. 93, pp. 4185-4190, 2003 
[14]. M. Terrones, N. Grobert, J. Olivares, J. P. Zhang, H. Terrones, K. Kordatos, W. K. Hsu, J. P. Hare, P. D. Townsend, K. Prassides, A. K. Cheetham, H. W. Kroto and D. R. M. Walton, "Controlled production of aligned-nanotube bundles", Nature, vol. 388, pp. 52-55, 1997.

[15]. N. Grobert, M. Terrones, S. Trasobares, K. Kordatos, H. Terrones, J. Olivarez, J. P. Zhang, Ph. Redlich, W. K. Hsu, C. L. Reeves, D. J. Wallis, Y. Q. Zhu, J. P. Hare, A. J. Pidduck, H. W. Kroto and D. R. M. Walton, "A novel route to aligned nanotubes and nanofibres using laser-patterned catalytic substrates", Appl. Phys. A, vol. 70, pp. 175-183, 2000.

[16]. Y. Gao, J. Liu, M. Shi, S. H. Elder and J. W. Virden, "Dense arrays of well-aligned carbon nanotubes completely filled with single crystalline titanium carbide wires on titanium substrates", Appl. Phys. Lett., vol. 74, pp. 3642-3644, 1999.

[17]. Ch. Emmenegger, P. Mauron, A. Zu“ ttel, Ch. Nu" tzenadel, A. Schneuwly, R. Gallay and L. Schlapbach, "Carbon nanotube synthesized on metallic substrates", Appl. Surf. Sci., vol. 162- 163, pp. 452-456, 2000.

[18]. X. H. Chen, S. Q. Feng, Y. Ding, J. C. Peng and Z. Z. Chen, "The formation conditions of carbon nanotubes array based on FeNi alloy island films", Thin Solid Films, vol. 339, pp. 6-9, 1999

[19]. C. Emmenegger, J. M. Bonard, P. Mauron, P. Sudan, A. Lepora, B. Grobety, A. $\mathrm{Zu}$ " ttel and L. Schlapbach, "Synthesis of carbon nanotubes over Fe catalyst on aluminium and suggested growth mechanism", Carbon, vol. 41, pp. 539$547,2003$.

[20]. S. Li, H. Liu, H. Li, J. Zhai, L. Jiang and D. Zhu, "The controlled pattern growth of aligned carbon nanotubes", Synth. Met., vol. 135-136, pp. 815-816, 2003.

[21]. P. M. Campbell, E. S. Snow and J. P. Novak, "Simple catalyst for the growth of small-diameter carbon nanotubes", Appl. Phys. Lett., vol. 81, pp. 4586-4588, 2002.

[22]. Z. P. Huang, D. L. Carnahan, J. Rybczynski, M. Giersig, M. Sennett, W. Z. Wang, J. G. Wen, K. Kempa and Z. F. Ren, "Growth of large periodic arrays of carbon nanotubes", Appl. Phys. Lett., vol. 82, pp. 460-462, 2003.

[23]. S. Huang, A. H. W. Mau, T. W. Turney, P.A. White and L. Dai, "Patterned growth of well-aligned carbon nanotubes: a softlithographic approach", J. Phys. Chem. B, vol. 104, pp. 2193-2196, 2000.

[24]. H. Ago, K. Murata, M. Yumura, J. Yotani and S. Uemura, "Ink-jet printing of nanoparticle catalyst for siteselective carbon nanotube growth", Appl. Phys. Lett., vol. 82, pp. 811-813, 2003.

[25]. H. M. Cheng, F. Li, X. Sun, S. D. M. Brown, M. A. Pimenta, A. Marucci, G. Dresselhaus and M. S. Dresselhaus, "Bulk morphology and diameter distribution of single-walled carbon nanotubes synthesized by catalytic decomposition of hydrocarbons", Chem. Phys. Lett., vol. 289, pp. 602-610, 1998.

[26]. H. Q. Yang, S. Bai, T. Fournier, F. Li, G. Wang, H. M. Cheng and J. B. Bai, "Direct growth of macroscopic fibers composed of large diameter SWNTs by CVD", Chem. Phys. Lett., vol. 370, pp. 274-279, 2003.

[27]. H. Ago, S. Ohshima, K. Uchida, T. Komatsu and M. Yumura, "Carbon nanotube synthesis using colloidal solution of metal nanoparticles", Physica B, vol. 323, pp. 306-307, 2002 .

[28]. P. Nikolaev, M. J. Bronikowski, R. K. Bradley, F. Rohmund, D. T. Colbert, K. A. Smith and R. E. Smalley, "Gas- phase catalytic growth of single-walled carbon nanotubes from carbon monoxide", Chem. Phys. Lett., vol. 313, pp. 91-97, 1999.

[29]. M. J. Bronikowski, P. A. Willis, D. T. Colbert, K. A. Smith and R. E. Smalley, "Gas-phase production of carbon single-walled nanotubes from carbon monoxide via the HiPco process: A parametric study”, J. Vac. Sci. Tech. A, vol. 19, pp. 1800-1805, 2001. 